\title{
The Time of Science and the Time of Speculation: A Comparative Study
}

\section{Zhu Hong Z*}

Associate professor in School of Philosophy, Wuhan University, PR China

*Corresponding author: Zhou, Zhuhong, School of Philosophy, Wuhan University, Hubei Province 430072, P.R. China, Tel: +86-15337236031; Email:

\section{Conceptual Paper}

Volume 1 Issue 2

Received Date: November 24, 2018

Published Date: December 17, 2018

DOI: $10.23880 /$ phij-16000111 zhouenya@msn.com

\section{Abstract}

Scientific time is the reading of clocks. Clocks embody the uniformity attribute of time. This is an argumentation in a circle. The method of transcending this circle is by reflecting on the history of the formation of scientific time. The reflection on history attributes scientific time to the measurement of change, the uniformity of which is determined by its Intrinsically no difference.

Dialectic time, the essence of time or the notion of time, is intuited becoming or change per se. Change or becoming is the unity of coming-to-be, which is from nothing to being, and passing away, which is from being to nothing. The nature of change is the negative of negation, or self-determining. The self-determining of change has a result. This result turns into the first determination that can be held assuredly, in other words, being determinate (Dasein). The nature of time is the same as that of change; it is absolute negation and self-determining.

The other essential determination of scientific time is finite. This is determined by the definition of scientific time and the determination of change; Dialectic time means eternal, i.e., the eternal present, and implies the eternal spirit of change, which creates and self-determines and presents itself in the present.

Is time finite or infinite? It is food for thought. Many famous ideologists have thought that time is the period from ancient to now. The opinion of finite time or infinite time has dominated the history of human ideas alternately. For example, people in general think time is infinite, affected by Newton's idea of time in the modern day; however, recent breakthroughs in cosmology suggest that time has a beginning and an end, or that time is finite.

Above all, we should confirm the nature of time before answering this longstanding question. There are different idea latitudes to reflect time, such as common sense, art, religion, science, and philosophic speculation. Generally, speculation on time in science is the key to other types of speculation. Hence, our reflection on time starts with scientific time. 


\section{The Definition of Scientific Time}

Scientific time can be defined as time that can be measured by clocks. Scientific time is the measurement of time, or which is essentially capable of observation.

The time definition "Absolute, true, and mathematical time, of itself, and from its own nature flows equably without regard to anything external, and by another name is called duration:" , is generally regarded as Newton's definition of time in science. This is a huge misconception. Newton said immediately that "relative, apparent, and common time, is some sensible and external (whether accurate or unequable) measure of duration by the means of motion, which is commonly used instead of true time; such as an hour, a day, a month, a year". This time belongs to Newton's scientific system, which is relative and is the measure of duration. Absolute and true time is speculation of time or the idea of time. The crisis of Newton's scientific time does not relate to the definition of time but to the definition of simultaneity. Newton premised the definition of simultaneity on instantaneous spread of light. This premise had been doubted by research scientists during Newton's period.

Generally speaking, the theory of relativity has revolutionized the idea of absolute time. However, we have reason to believe that relativity does not put an end to the measurability of time in science. Einstein specially insists that the definition of time in science should depend on measure not on speculation. He said that "We are thus led also to a definition of "time" in physics. For this purpose we suppose that clocks of identical construction are placed at the points $A, B$ and $C$ of the railway line (coordinate system), and that they are set in such a manner that the positions of their pointers are simultaneously (in the above sense) the same. Under these conditions we understand by the "time" of an event the reading (position of the hands) of that one of these clocks which is in the immediate vicinity (in space) of the event. In this manner a time-value is associated with every event which is essentially capable of observation." ${ }^{1}$ The time of relativity is the reading of the horologe, which measures time. Relativity also has defined coordinate- time, proper- time, and simultaneity by means of reading of the horologe.

Time in quantum theory is the time of measurement also. It can be measured by clocks as well. According to quantum mechanics, in principle, it is impossible to build

\footnotetext{
${ }^{1}$ Albert Einstein, Relativity: The Special and General Theory; $a$ popular exposition , trans, Robert WL(London: London Methuen), pp: 23.
}

\section{Philosophy International Journal}

a bell that can measure the time within the Planck scale. This implies that within the Planck scale there is no definition of measurable time. Hence, time that is not within the Planck scale has no significance, or does not exist.

Quantum cosmology comes into being on the foundation of general relativity and quantum, the time definition of which is reading of the horologe following that of relativity and quantum.

Distinguishing scientific time and philosophic time is very important to the perspicuity and profundity of thought.

\section{The time of dialectics is the change per se}

Time is not only the core concept in science but also occupies a very significant part in philosophy, especially in the theory of dialectics. In the opinion of the great dialectics, nature and spirit are "everliving fire", change, and development of the self since Heraclitus. The aim of dialectic reason is to look for a universal philosophic language to appreciate change. In Hegel's dialectics, time is just change per se, or coming-to-be and passing-away of the self. Then how do the time of science and the time of dialectics communicate and understand each other?

The definition of time in science is simple and deep. Time is the reading of the horologes. What are horologes? The circular movement of uniformity as a horologe embodies the uniform attribute of time. Time is defined by a horologe, whereas horologe is determined by time attribute. This is an argumentation in a circle. We may transcend this circle by reflecting on the history of formation of scientific time. From year, month, day, to atomic clock, it is obvious that humans measure change by circular movements in nature, which are increasingly uniform. The reading of the horologe, as in scientific time, is the abstract to the circular movements. Thus, it can be seen that scientific time is the measurement of change.

What is the essence of time or the notion of time? We may ponder on this question according to Hegel's dialectics time. In Hegel's view, time is intuited becoming or change per se. He explained: "Everything, it is said, comes to be and passes away in time. If abstraction is made from everything, namely from what fills time, and also from what fills space, then what we have left over is empty time and empty space: in other words, these abstractions of externality are posited and represented as if they were for themselves. But it is not in time that everything comes to be and passes away, rather time 


\section{Philosophy International Journal}

itself is the becoming, this coming- to-be and passing away, the actually existent abstraction, Chronos, from whom everything is born and by whom its offspring is destroyed." "Time is not, as it were, a receptacle in which everything is placed as in a flowing stream, which sweeps it away and engulfs it. Time is only this abstraction of destruction. It is because things are finite that they are in time; it is not because they are in time that they perish; on the contrary, things themselves are the temporal, and to be so is their objective determination. It is therefore the process of actual things themselves which makes time; and though time is called omnipotent, it is also completely impotent."2 Hence, the essence of time or the notion of time is change per se.

Time is determined by change and how do we determine change (Das Werden)? In Hegel's logic, "Becoming is the first concrete thought, and therefore the first notion:" 3 . Real concrete thought, or real notion, must be determined by self-negation or the negative of that negation. Becoming is determined just by the transition between two notions: being and nothing. The unity, coming-to-be, which is from nothing to being, and passing away, which is from being to nothing, is change or becoming.

Becoming, as the first "Notion, however, in its freely self-existent identity as $\mathrm{I}=\mathrm{I}$, is in and for itself absolute negativity and freedom" ${ }^{4}$. I=I means self-determining. The self-determining of change has result. This result turns into the first determination that can be held assuredly, which is being determinate (Dasein), or the determination of quality. "in Becoming the Being which is one with Nothing, and the Nothing which is one with Being, are only vanishing factors; they are and they are not. Thus by its inherent contradiction Becoming collapses into the unity in which the two elements are absorbed. This result is accordingly Being Determinate (Being there and so)"5.

Time, like change, is absolute negativity or selfdetermining. "Time is the same principle as the I=I of pure self-consciousness" 6 . However, time is not becoming; only the notion of time or the nature of time is becoming. Time-self is the intuited becoming, or a pure form of sense or intuition, the nonsensuous sensuous. Hence, the absolute negativity or self-determining of time is exterior.

${ }^{2}$ Hegel GWF, Hegel's Philosophy of Nature, trans. A.V. Miller (Oxford: Oxford University Press 2004), pp: 36.

${ }^{3}$ Hegel GWF, The Logic of Hegel, trans. William Wallace (Oxford: Oxford University Press 1892), pp: 167.

${ }^{4}$ Hegel GWF, Hegel's Philosophy of Nature, pp: 35.

${ }^{5} \mathrm{Hegel}$ GWF, The Logic of Hegel, pp: 169.

${ }^{6}$ Hegel GWF, Hegel's Philosophy of Nature, pp: 35.
The result of which is the unit of measurement, the reading of the horologe, namely, scientific time. "The principle of time is only capable of being so expressed when the Understanding has paralysed it and reduced its negativity to the unit. This inert One, the utter most externality of though, can be used to form external combination, and these, the numbers of arithmetic, can in turn be brought by the Understanding under the categories of equality and in-equality, of identity and difference"7.

Time is the foundation of arithmetic. We know that the groundwork of math edifice is the theory of real numbers, which is the root of arithmetic. Math is the theory of quantity-the science of measurement. Its inherent basis is time. Hence, we can understand why time is a pure form; math is the science of form or the science of time.

The math of space is geometry. By analytic geometry, geometry can use in real number theory, i.e., the theory of time. The history of scientific ideas has showed that space can transform to time; time is more basal than space. This is just the view of Hegel to the relation of time and space. "The truth of space is time, and thus space becomes time; the transition to time is not made subjectively by us, but made by space itself. In pictorial thought, space and time are taken to be quite separate: we have space and also time; philosophy fights against this "also"”"8.

Hence, why is the unit of time uniform? The reason is that there is no difference inside time-self. "Time is continuous, too, like space, for it is the negativity abstractly relating self to self, and in this abstraction there is as yet no real difference" ${ }^{\prime \prime}$. The continuous may be regarded as the abstract of uniformity.

Becoming is determined as quality or something. Time is determined as quantity or the form of something. Becoming is the notion of time or the nature of time. Time is the intuited becoming or the measure of time. It is easy to deduce Hegel's view of the relationship between times with matter-motion: time is the form of matter-motion.

Hegel's dialectics tell us that time determines and is determined by matter-motion. Yet, how do they determine each other? This work has been accomplished by science.

\footnotetext{
${ }^{7}$ Hegel GWF, Hegel's Philosophy of Nature, pp: 38. ${ }^{8} \mathrm{Hegel} \mathrm{GWF}$, Hegel's Philosophy of Nature, pp: 35. ${ }^{9}$ Hegel GWF, Hegel's Philosophy of Nature, pp: 35.
} 


\section{Time-space determines and is determined by matter-motion}

We know that absolute time, from its own nature flows equably without regard to matter-motion, is simply Newton's speculation of the nature of time; time, attributed to Newton's scientific system, is relative and the measure of motion. To Newton, time and mattermotion are certainly related. However, this relationship is exterior, similar to the one using time to measure motion subjectively. Hence, Newton's scientific system does not show the indiscerptible immanent relationship of time with matter-motion.

The most revolutionary ideas of Einstein's theory is that time and matter-motion is an immanent unity. Especially, in relativity, time and space is a unity of fourdimensional time-space; energy and momentum is the unity of four-dimensional momentum. Furthermore, in general, relativity time-space determines and also is determined by energy-momentum; universal gravitation is not the real force, but the representation of the curvature of time-space. Besides, in Hawking's quantum cosmology, gravity is just the classical effect of the curvature of space-time; radiation, which would appear where two different time-space topologies transform, is the quantum effect of time-space structure.

The effect of pure gravity would make stars collapse into black holes, from which nothing can escape including light. However, Hawking has proved that if we consider the quantum effect of nontrivial time-space topologies, black holes are not black, have emission, and may disappear in certain conditions. It is a miracle that the nature of space-time makes gravitation and emission seem closely related.

\section{The relative time and the absolute time in relativity}

Relativity not only defines time but also defines coordinate time, simultaneity, and proper time. Generally speaking, relativity shows the relativity of time, which means the relativity of coordinate time and simultaneity.

Certainly in relativity, a coordinate-time would be different relative to a different reference-body (coordinate systems), or clocks of identical construction, which rest or move following different coordinate systems, and have different time-values or readings. Hence, each coordinate system has its own particular time. Yet, the fact that clocks are the natural processes of uniform circle has not changed.

Indeed, simultaneity is relative. Events that are simultaneous with reference to a coordinate system may be not simultaneous with respect to the other system and vice versa. However, it is not serious. Relativity has proven that relativity of simultaneity will not destroy the causality.

Proper time $e^{10}$ has special significance in relativity. Proper time represents the real time that any event has gone through. The time that the event has experienced is different with respect to different coordinate systems. However, the proper time of this course is one and only and does not change along with coordinate systems, which depends on the length of the world line ${ }^{11}$ itself.

In relativity, there are two very famous principles: the principle of relativity (in the restricted sense) ${ }^{12}$ and the general principle of relativity ${ }^{13}$. The central idea of these principles is that the general laws of nature are absolute and changeless. Now we know that proper time is the real time that corresponds with the course of events, which is only and absolute. Relativity should be called as absolutism: There are absolute natural laws, as well as absolute time.

Now, we can reflect on the issue that time is finite or infinite in science according to proper time.

\section{The issue "Is time finite or infinite?" is a pseudo-question.}

As I have mentioned, in Newton's scientific system, the relationship between time and matter-motion is exterior. Time is simply continuous. It is natural to think that time goes on forever.

The situation, however, is quite different in the general relativity theory of Einstein. Space and time are now dynamic quantities, or space-time and matter-motion determine each other. It means that space and time not only affect but also are affected by everything that

\footnotetext{
${ }^{10}$ In terms of four-dimensional space-time, proper time is analogous to arc length in 3-dimensional Euclidean space.

${ }^{11}$ The world line of an object is the unique path of that object as it travels through 4-dimensional space-time. World lines are a general way of representing the course of events.

12If, relative to $K, K^{\prime}$ is a uniformly moving coordinate system devoid of rotation, then natural phenomena run their course with respect to $K$ ' according to exactly the same general laws as with respect to $K$. ${ }^{13}$ All Gaussian coordinate systems are essentially equivalent for the formulation of the general laws of nature.
} 


\section{Philosophy International Journal}

happens in the universe. Hence, it becomes meaningless to talk about the nature of time without matter-motion.

Furthermore, in Hawking's quantum cosmology, the world lines of stars and that of the universe-self will break off inevitably at the singularities of space-time where stars collapse to become black holes or the universe originates. The world line of everything that happens in the universe or the universe-self represents its proper time. Hence, the world line of an event breaking off means that the event time has an end. We may say that at least now time is finite in science.

The chief reason why scientific time is finite is that the time that is significant in science is created by the process of matter-motion; proper time cannot be separated from matter-motion, but not the relative time that will change along with different observations or coordinate systems. This point of view about the relationship between time and matter-motion accords with that of dialectic reason. As Hegel has said, "things themselves are the temporal" and "the process of actual things themselves which makes time".

In addition, scientific reason believes that all natural things are finite and must experience the process of coming-to-be and passing away. Hence, the time of each special natural thing in the universe is finite. Moreover, the new understanding of space-time in modern cosmology makes us believe that the universe-self will experience the process of coming-to-be and passing away as well. Hence, it is natural to deduce that the time of the universe is finite.

At one point in time, space and time were thought of as a fixed arena in which everything come- to-be and pass away independently, but space-time self was infinite and forever. As soon as space and time are thought of as the course of coming-to-be and passing away self, and everything in the universe including the universe-self experiences the process of coming- to-be and passing away, the issue "Is time finite or infinite?" becomes a pseudo-question in science. Because the time-self just means finite.

\section{The reason why we cannot understand finite-time}

The first reason why we cannot understand finite-time is that one's questioning rests with the kind of intuitional extrapolation. People may doubt that even if the universe has a beginning or an end, and if so, what happened before then? What will happen after then?
In Hawking's opinion, nothing exists outside the universe, absolutely nothing at all. We, as observers, cannot see the whole of the universe. If there is an intellectual intuition (like God) who can look outside the universe, he would see the wave function of the universe that shows all the possibilities, not earth, stars, sky, etc., ... as we observe.

Hegel regards the kind of intuitional extrapolation as bad-infinite. He said: "When time and space, for example, are spoken of as infinite, it is in the fires place the infinite progression on which our thoughts fasten. We say, Now, This time, and then we keep continually going forwards and backwards beyond this limit. ... It is true indeed that we must abandon the unending contemplation, ... We lay down a limit; then we pass it; next we have a limit once more, and so on forever. All this is but superficial alternation, which never leaves the region of the finite behind"14. In fact, this infinite, which is extrapolated from the finite intuitionally, is only the finite. This refers to another reason for this question, namely, lowering the infinite to the finite.

Secondly, Hegel thinks that obtaining the infinite by increasing the finite without end opposes the finite with the infinite, making the finite determine the infinite. In this way, "the infinite is thereby only one of two, and is reduced to a particular, to which the finite forms the other particular. Such an infinite, which is only a particular, is coterminous with the finite which makes for it a limit and a barrier: it is not what it ought to be, that is the infinite, but is only finite.", then "an equal dignity of permanence and independence is ascribed to finite and to infinite", and more "There must be an abyss, an impassable gulf between the two, with the infinite abiding on yonder side and finite steadfast on this"15.

\section{The infinite of dialectic reason}

The infinite of dialectic reason is developing the useful and discarding the useless to the finite, and the selfnegating of finite. "If we further say that infinite is the not finite, we have in point of face virtually expressed the truth; for as the finite itself is the first negative, the notfinite is the negative of that negation, the negation which is identical with itself and thus at the same time a true affirmation" 16 . Finite implies being determinate, or something, which has the determination of quality. Determinate-self should be regarded as negative, because

\footnotetext{
${ }^{14}$ Hegel GWF, The Logic of Hegel, pp: 174.

${ }^{15}$ Hegel GWF, The Logic of Hegel, pp: 176.

${ }^{16}$ Hegel GWF, The Logic of Hegel, pp: 176.
} 


\section{Philosophy International Journal}

it determines the limit of something-being. Hence, the finite is negation. Because of the contradiction of itself, the finite would transcend its limit to come its other and then come back itself from its other endlessly. This process can be enunciated as the real infinite. Hence, the real infinite is the negative of that negation. "But such a progression to infinite is not the real infinite. That consists in being at home with itself in its other, or, if enunciated as a process, in coming to itself in its other"17. "Something in its passage into other only joins with itself. To be thus self - related in the passage, and in the other, is the genuine infinity"18.

It is obvious that in Hegel's view, the real infinite is the self-negation of the finite. When a finite thing is able to create its other, and then come back itself, it would obtain infinity, which is the embodiment of notion and spirit, for example, life. Nature life is finite. Birth and death is its limit. However, the growth of a life is a process of selfactivity, self-determination, self-preservation, and selfnegation, and then is infinite as well. Therefore life, as nature-being, is the highest flower in nature. It has not only the nature-being but also the exhibiting spirit. The notion of self-determination finds out itself in life. So life may qualify as ideal. Referring to the finite, we may say that something is finite, existence is finite, and all naturebeings are finite. However, we cannot find any infinite beings. The infinite can be infinite radically. Hegel's infinity is the embodiment of dialectic reason, namely, self-negation.

\section{The finite and the infinite of dialectic time}

When we have comprehended the dialectic relationship of the finite with the infinite, the issue that time is finite or infinite becomes more transparent at once.

First, the issue whether time is finite or infinite is an artificial question in the scientific field according to the essential determination of scientific time. If we regard the nature of scientific time as the coming-to-be and passingaway self, then the notion of time in science includes the meaning of the finite. The temporal itself implies finite. "The finite, however, is temporal, it has a before and an after; and when the finite is our object we are in time. It has a beginning but not an absolute one; its time begins with it, and time belongs only to the sphere of finitude" 19 .

\footnotetext{
${ }^{17}$ Hegel GWF, The Logic of Hegel, pp: 175.

${ }^{18} \mathrm{Hegel}$ GWF, The Logic of Hegel, pp: 176.

${ }^{19}$ Hegel GWF, Hegel's Philosophy of Nature, pp: 15.
}

Secondly, dialectic reason can still discuss infinite time by philosophic speculation, namely, the notion of time. "But in its Notion, time itself is eternal; for time as such_ not any particular time, nor now _ is its Notion, and this, like every Notion generally, is eternal and therefore also absolute Presence" 20 . The notion of time is change, and is the negative of that negation. From this point of view, the present would be the unity of the past and the future. "But the concrete present is the result of the past and is pregnant with the future. The true present, therefore, is eternity"21. The real present is infinitude.

Conversely, the real infinitude, the real eternity, certainly shows itself in the present. Hegel gives an example: God is infinite spirit. How then has God come to create the world? We can conceive God as a subject far removed from the world. However, such a God is only an abstract infinity. Abstract infinity itself is just particular and finite. The real infinite God reveals Himself in two living ways: as nature and as spirit. "Both manifestations are temples of God which He fills, and in which He is present. God, as an abstraction, is not the true God, but only as the living process of positing His other, the world"22. Hence, the real "eternity is not before or after time, not before the creation of the world, nor when it perishes; rather is eternity the absolute present, the Now, without before and after. The world is created, is now being created, and has eternally been created; this presents itself in the form of the preservation of the world. Creating is the activity of the absolute Idea; the Idea of nature, like the Idea as such, is eternal" 23 . Because nature presents the infinite spirit.

\section{Brief summary}

In a word, we identify with Hegel's idea about the nature of time: space-time is the being-form of mattermotion; time-space determines and is determined by matter-motion. We have a deeper understanding of this idea by reflecting on the time of science and the time of dialectics.

Scientific time is the reading of clocks. Clocks embody the uniformity of time. This is an argumentation in a circle. The method of transcending this circle is to reflect on the history of formation of the idea of scientific time. The reflection of history attributes scientific time to the measurement of change, the uniformity of which is determined by its inherent indifference.

\footnotetext{
${ }^{20}$ Hegel GWF, Hegel's Philosophy of Nature, pp: 36

${ }^{21} \mathrm{Hegel} \mathrm{GWF}$, Hegel's Philosophy of Nature, pp: 39

${ }^{22}$ Hegel GWF, Hegel's Philosophy of Nature, pp: 13

${ }^{23}$ Hegel GWF, Hegel's Philosophy of Nature, pp: 15.
} 


\section{Philosophy International Journal}

Dialectic time, the essence of time or the notion of time, is intuited becoming or change per se. Change or becoming is the unity of coming- to-be, which is from nothing to being, and passing away, which is from being to nothing. The nature of change is the negative of negation, or self-determining. The self-determining of change has result. This result turns into the first determination that can be held assuredly, which is being determinate (Dasein). The nature of time is the same as that of change, is the absolute negation, and selfdetermining.

The other essential determination of scientific time is finiteness or timeliness. This is determined by the definition of scientific time and the determination of change; dialectic time means eternal, the eternal present, and implies the reason spirit that is eternal change, creating, self-determining, and presents itself at present. 